\title{
THERMAL AND STRESS ANALYSIS OF THE FARADAY SHIELD FOR THE ORNL/TFTR RF ANTENNA
}

\author{
C. J. Hammonds, B. E. Nelson, J. C. Walls, D. J. Hoftman, and F. W. Baity \\ Martin Marietta Energy Systems, Inr., P.O. Bax 2009, Oak Ridge, Tennessee 37831
}

\section{ABSTRACT}

The rf antenna designed and built by Oak Ridge National Laboratory (ORNL) for the Tokamak Fusion Test Reactor (TFTR) is an ion cyclotron respnance heating antenna operating in the 40 - to $80-\mathrm{MHz}$ frequency range with a power output of $4 \mathrm{MW}$ for a 2-s pulse. The antenna was delivered to Princeton in November 1987. A review of the antenna design began in early 1988 to ensure compatibility with D-T operation of TFTR. Owing to the serious consequences of a water leak during $D-T$ operation and to other concerns, it was concluded that the Faraday shield of the antenna should be rebuilt. In addition, because of increased heat loads and more stringent acceptance criteria, a new thermal and stress analysis of the shield was authorized.

\section{DESIGN DESCRIPTION}

The Faraday shield (Fig. 1) consists of a box frame weldment containing two horisontal rows of tubes. The tubes are arranged in a poloidal arc parallel to the surface of the plesma. The front-row tubes (or those closest to the plasma) are faced with graphite tiles. Additionel graphite-faced "bumpers" are arranged around

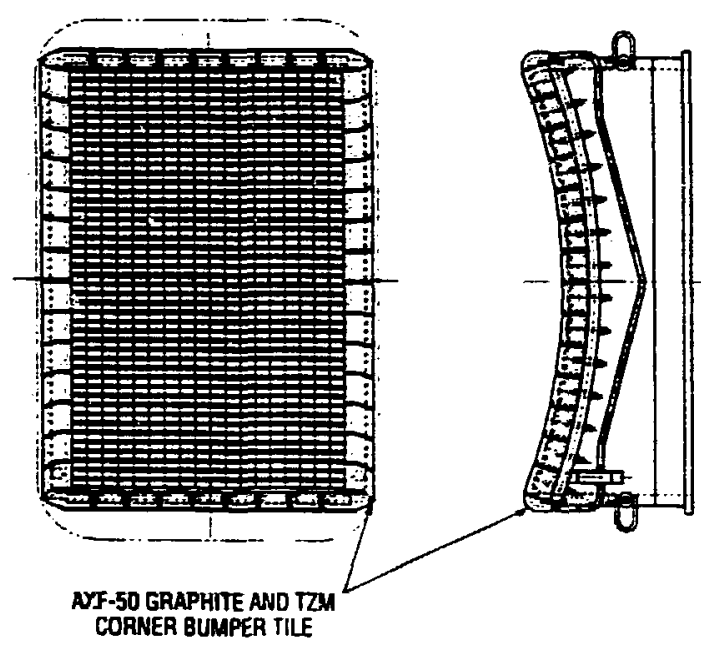

Fig. 1. ORNL/TFTR Faraday shield. the perimeter of the box facing the plasma. Manifolds at either end of the tubes connect to a demineralized water system that supplies a total of $38 \mathrm{gal} / \mathrm{min}$ at $20^{\circ} \mathrm{C}$ to cool the tubes. The tubes and box frame are made from Inconel 625. Critical features of the design include the graphite-to-Inconel tube braxe, the welds between the tube and the frame, the manifold welds, and the graphite bumpers.

\section{LOADS}

During operation, the Faraday shield is heated by if losses, direct plasma radiation, and particle flux. The shield is also thermally and mechanically stressed by plasma disruptions. The heat loads induce axial compression and bending in the tubes due to the restraint of thermal expansion imposed by the box frame. The plasme disruption induces eddy current loads that act primarily as a couple with equal and opposite vertical forces on the sides of the box. The eddy currents also result in running loads on the tubes directed toward the plasma.

Since uncertainty concerning the particle flux load existed during the analysis, the analysis was performed both with and without this load. The flux that intercepts the shield is a function of the plasma shape and the relation of the shield to the adjacent limiters. The "low- $T_{i}$ " mode loads are based on a vertically elongated plasma shape, and the "high-Ti" loads are based on a horizontally elongated plasma. The tubes should be protected from the particle flux in either case by the side bumpers.

The loads are summarized in Table I. During high$T_{i}$ load conditions, if loads are assumed to act in a sin ${ }^{2}$ distribution, peaking at the top and bottom of the tube on the front half, and the particle flux and radiation load are assumed to ect normal to the shield (radially out from the plasma).

\section{MATERIĀ́ PROPERTIES AND LIMITS}

In order to perform the analysis and evaluate design margins and fatigue life, the material properties and allowable streases must be defined. The primary materials are Inconel 625 and $A X F-5 Q$ graphite. The Faraday

-Research aponsored by the Office of Fusion Energy, U.S. Department of Energy, under contract DE-AC05-84OR21400 with Martin Merietta Energy Syatems, Inc. 
Table I. Assumed operating loads on the Faraday shield

\begin{tabular}{|c|c|c|}
\hline Load $^{n}$ & Magnitude & No. of cycles \\
\hline Internal pressure & 300 psi & $10^{3}$ \\
\hline $\begin{array}{l}\text { Disruption load: } \\
\text { On front tubes } \\
\text { On rear tubes }\end{array}$ & $\begin{array}{l}2.6 \mathrm{lb} / \mathrm{in} . \\
4.07 \mathrm{lb} / \mathrm{in} .\end{array}$ & $\begin{array}{l}10^{4} \\
10^{4}\end{array}$ \\
\hline $\begin{array}{l}\text { Disruption couple } \\
\text { on box frame }\end{array}$ & $14000 \mathrm{lb}$ & $10^{4}$ \\
\hline $\begin{array}{l}\text { Maximum rf power: } \\
\text { On front tubes } \\
\text { On rear tubes }\end{array}$ & $\begin{array}{l}76.3 \mathrm{~W} / \mathrm{cm}^{2} \\
34.3 \mathrm{~W} / \mathrm{cm}^{2}\end{array}$ & $\begin{array}{l}10^{5} \\
10^{5}\end{array}$ \\
\hline $\begin{array}{l}\text { Plasma heat (low } T_{1} \text { ): } \\
\text { Shield tubes } \\
\text { Vertical bumpers } \\
\text { Horizontal bumpers }\end{array}$ & $\begin{array}{l}50 \mathrm{~W} / \mathrm{cm}^{2} \\
830 \mathrm{~W} / \mathrm{cm}^{2} \\
100 \mathrm{~W} / \mathrm{cm}^{2}\end{array}$ & $\begin{array}{l}10^{5} \\
10^{8} \\
10^{6}\end{array}$ \\
\hline $\begin{array}{l}\text { Plasma hest (high } T_{\mathrm{i}} \text { ): } \\
\text { Shield tubes } \\
\text { Vertical bumpers } \\
\text { Horizontal bumpers }\end{array}$ & $\begin{array}{l}257 \mathrm{~W} / \mathrm{cm}^{2} \\
2500 \mathrm{~W} / \mathrm{cm}^{2} \\
767 \mathrm{~W} / \mathrm{cm}^{2}\end{array}$ & $\begin{array}{l}10^{4} \\
10^{4} \\
10^{4}\end{array}$ \\
\hline
\end{tabular}

a Plasma loads decay with a 1-cm efold length for low $T_{i}$ and a $2-\mathrm{cm}$ length for high $T_{i}\left(Q=Q_{0} e^{-R / 2 \mathrm{~cm}}\right)$. Loads are assumed to act simultaneously. The assumed boundary conditions are: water flow rate, $38 \mathrm{gal} / \mathrm{min}$; water inlet temperature, $70^{\circ} \mathrm{F}$; and radiation to surfaces at $300^{\circ} \mathrm{F}$.

shield had to comply with the ASME Boiler and Preasure Vessel (B\&PV) ${ }^{1}$ Code where applicable. Although this is a stringent requirement, the B\&PV Code does include allowances for the self-relieving nature of the thermal stresses and the limited number of fatigue cycles that must be exdured. It does not consider the fact that the fatigue atresses are not fully reversed and in many areas are primarily in compreasion. The interpretation of the code for the Inconel tubes and welds is summarized in Table II. Graphite is not covered by the ASME code.

\section{ANALYSIS APPROACH}

The anaiysis focused on the primary design concerns and included (1) temperature response oi the tubes, grophite, and Inconel; (2) temperature response of the graphite bumpers; (3) streses in the graphite tiles; (4) streases in the tubes and tube welds; (5) stresues in the box and manifold welds; and (6) atresses in the bumpers. The results are based on several computer models that reflected both the original and the modified desigm. The primary modification is the reduction in cross section of the rear tubes. The models were loaded with the worst-case combination of all loads for both high- $T_{\mathfrak{i}}$ and low- $T_{\mathfrak{i}}$ heat fluxes.
Table II. Faraday shield stress calegories

\begin{tabular}{|c|c|c|c|c|}
\hline $\begin{array}{l}\text { Loading } \\
\text { event }\end{array}$ & \multicolumn{2}{|c|}{$\begin{array}{l}\text { Type of } \\
\text { load }\end{array}$} & $\begin{array}{l}\text { Stress } \\
\text { category }\end{array}$ & $\begin{array}{l}\text { No. of } \\
\text { cycles }\end{array}$ \\
\hline $\begin{array}{l}\text { Internal } \\
\text { pressure }\end{array}$ & \multicolumn{2}{|c|}{ Hoop, $F_{t}$} & $P_{m}$ & $10^{3}$ \\
\hline $\begin{array}{l}\text { Disruption: } \\
\text { Frame torque } \\
\text { Tube loading }\end{array}$ & \multicolumn{2}{|c|}{$\begin{array}{l}\text { Bending, } M_{2} \\
\text { Bending, } M_{1}\end{array}$} & $\begin{array}{l}Q_{b} \\
P_{b}\end{array}$ & $\begin{array}{l}10^{4} \\
10^{4}\end{array}$ \\
\hline RF heating & \multicolumn{2}{|c|}{$\begin{array}{l}\text { Thermal, } F_{\mathbf{x}} \\
\text { Thermal, } F_{i}\end{array}$} & $\begin{array}{l}P_{m}, Q_{m} c \\
F\end{array}$ & $\begin{array}{l}10^{5} \\
10^{5}\end{array}$ \\
\hline Plasma heating & \multicolumn{2}{|c|}{$\begin{array}{l}\text { Thermal, } F_{x} \\
\text { Thermal, } M_{1} \\
\text { Thermal, } F_{i}\end{array}$} & $\begin{array}{l}P_{m}, Q_{m} c \\
Q_{b} \\
F\end{array}$ & $\begin{array}{l}10^{5} \\
10^{5} \\
10^{5}\end{array}$ \\
\hline \multicolumn{4}{|c|}{$\begin{array}{c}\text { Allowables for Inconel } 625 \text { at } \\
\text { room temperature }\end{array}$} & \\
\hline & Category & Base metal & Weld & \\
\hline \multicolumn{2}{|c|}{$\overline{P_{m}}$} & 36 & 18 & \\
\hline \multirow{2}{*}{\multicolumn{2}{|c|}{$\begin{array}{l}P_{m}+P_{b} \\
P+Q\end{array}$}} & 54 & 27 & \\
\hline \multirow{2}{*}{\multicolumn{2}{|c|}{$\begin{array}{l}P+Q \\
\text { Peak range } \\
\left(10^{5} \text { cycles }\right)\end{array}$}} & 108 & 54 & \\
\hline & & 146 & 73 & \\
\hline
\end{tabular}

a $F_{2}=$ axial force; $M_{1}, M_{2}=$ moments about vertical and radial axes; $F_{i}=$ local forces.

${ }^{6} P_{m}, P_{b}=$ primary membrane and bending stresses; $Q_{m}, Q_{b}=$ secondary membrane and bending stresses; $F=$ peak local stresa increases due to stress concentrations or hot spots.

ePrimary stress in welds due to elastic buildup in tube.

\section{FARADAY SHIELD TUBE ANALYSIS}

The thermal stresses were evaluated in the POCO AXF-5Q graphite tiles, which are brased to the Faraday shield Inconel cooling tubes. The evaluation included determination of residual stresses present from the braxing process itself. Residual stresses were evaluated for a fully bonded graphite tile and also for tiles with simulated 90 and $80 \%$ bonding between the tile and the Inconel tube. Streses resulting from the thermal gradients present during the low- $T_{\mathrm{i}}$ mode of operation were also obtained. These stresses were then combined with the residual states of stress for evaluation against failure criteria for both static and cyclic loading conditions.

A two-dimengional (2-D) finite-element model was formulated for evaluation of the stresses in the graphite tiles bonded to the Inconel tubes. The model (Fig. 2) shows the number of elements used and the $150^{\circ}$ tile and tube sections. Becsuse of symmetry, only one-half of the tube and tile were modeled. The model was 


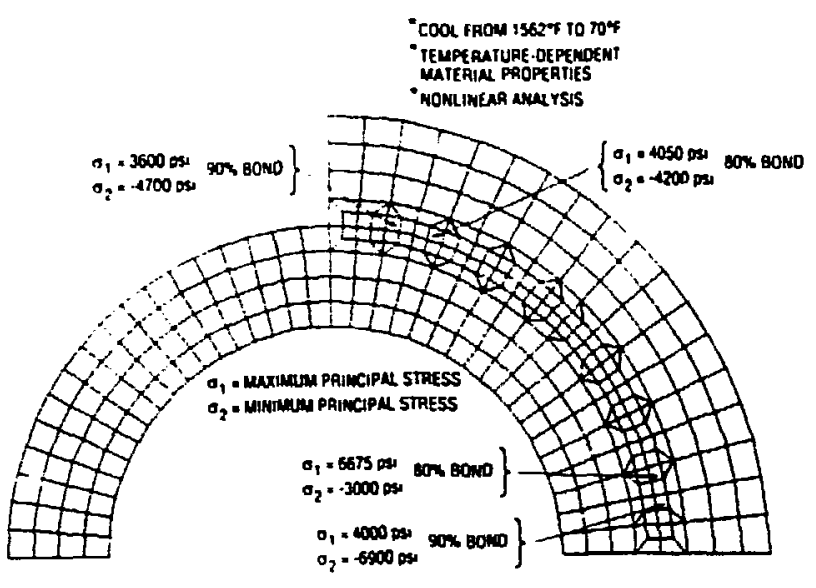

Fig. 2. Faraday tube 2-D model.

formulated with the PDA/PATRAN preprocessor code and translated to an MSC/NASTRAN code input for the thermal and stress solutions obtained. The model contains $\mathbf{2 7 0}$ quadrilateral elements, 30 triangular elements, and 338 grid points.

Temperature distributions throughout the graphite tile and water-cooled Inconel tube were obtained by a transient thermal analysis solution technique in MSC/NASTRAN. The time-dependent heating fluxes from the if and plasma loadings were imposed on the tile surface. Stress solutions were obtained at various time points by using the stress solutions available within the MSC/NASTRAN code.

\section{Braze Stress Analysis}

A study of the resulting residual stresses present in the graphite tile as the tile and tube are cooled from the brace temperature of $1562^{\circ} \mathrm{F}$ to $70^{\circ} \mathrm{F}$ was conducted with the 2-D model described above. Five separate residual stress solutions were obteined. One solution assumed that a perfeet bond was present between the tile and the tube as cooling occurred. The other four solutions simulated values of 90 and $80 \%$ bonding at the centerline of the tube and at the edge of the graphite tile. This simulation of a percentage of debonding between tile and tube was done by "disconnecting" the appropriate interfacing tile and tube elements in the finite-element model.

Maximum and minimum principal streaves at peak streas locations in the graphite tile are aleo shown in Fig. 2 for the four different bonding assumptions made. The results indicate that an area of debonding near the center of the tube-tile interface creates higher residual stresess than the same percentage of debonding at the tile edge. Also, higher strewes result from a greater amount of debonding.

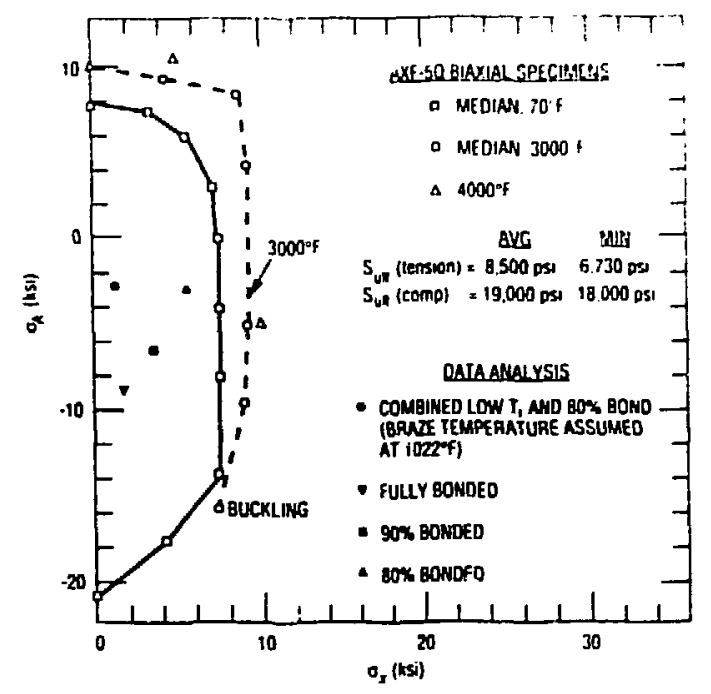

Fig. 3. Peak combined and residual stresses vs failure criteris for AXF-5Q graphite.

The maximum and minimum values of principal stress for the different bonding assumptions are plotted in Fig. 3, along with a plot of failure data for AXF-5Q graphite at both room temperature and higher temperatures. Examination of the results shows that, as the amount of debonding increases (or amount of bonding decreases), the maximum principal stress state in the graphite tile approaches the median failure line. Also shown in Fig. 3 are average and minimum strength values for the graphite. The maximum obtained value of principal stress was 6675 pai for the $80 \%$ bond assumption. This value of stress is still less than the given minimum tensile strength value of $6730 \mathrm{psi}$.

\section{Low- $\boldsymbol{T}_{\mathbf{i}}$ Heating Mode Analysis}

The 2-D tube model was also used to evaluate the imposed heat fluxes from the low- $T_{i}$ heating mode. The distribution of heat flux vs time for this mode is shown in Fig. 4.

With the heating fluxes imposed on the face of the graphite tile, MSC/NASTRAN was used to solve for temperatures vs time in the model. The boundary conditions assumed were a water flow of $26 \mathrm{gal} / \mathrm{min}$ in the tube and an initial temperature of $20^{\circ} \mathrm{C}$.

A peak temperature of $455^{\circ} \mathrm{F}$ was seen after $4 \mathrm{~s}$ in the graphite at the centerline of the tile. With this temperature distribution, atress solutions were obtained with the MSC/NASTRAN model. Stresses were obtained for the low- $T_{\mathbf{i}}$ heating mode with and without the effect of brace residual stresses along with low- $T_{i}$ heating. Results for a perfect brase ( $100 \%$ bonding between graphite tile and Inconel tube) and a simulation for an $80 \%$ bond were developet. 


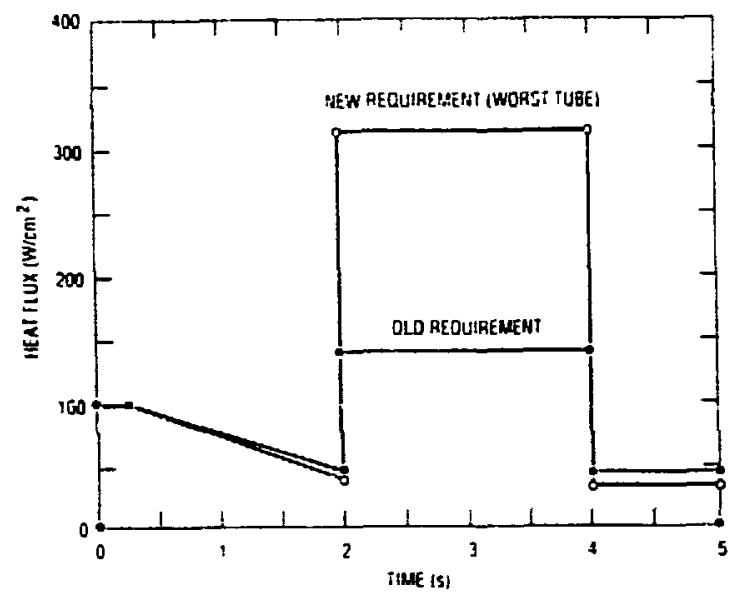

Fig. 4. Low- $T_{i}$ hest flux distribution.

Figure 3 shows the peak combined stressea, along with the residual streas states, to illustrate how the states of stress change when the low- $T_{i}$ heating fluxes are imposed. With the assumption of an $80 \%$ bond, the maximum tensile principal stress component is generally reduced from about 6000 pai to less than 2000 psi. Therefore, this range of stress indicates the variation that occurs as the heating fluxes are cycled throughout the life of the Faraday shield.

The proposed constant-life fatigue diagram of a $50 \%$ failure probsbility is shown in Fig. 5. The maximum and minimum states of stress in the graphite tile for 80 and $90 \%$ bond are plotted; a $90 \%$ bond state of stress is plotted on the $10^{5}$ cycles line and an $80 \%$ bond on the $10^{3}$ cycles line.

For the criteria given, this means that a $90 \%$ bond (braze) has a $50 \%$ probability of completing 100,000 cycles of loading without failure and that the $80 \%$ bond has a $50 \%$ probsbility of completing 1000 cycles without failure. The life diagram for graphite for $<1 \%$ failure

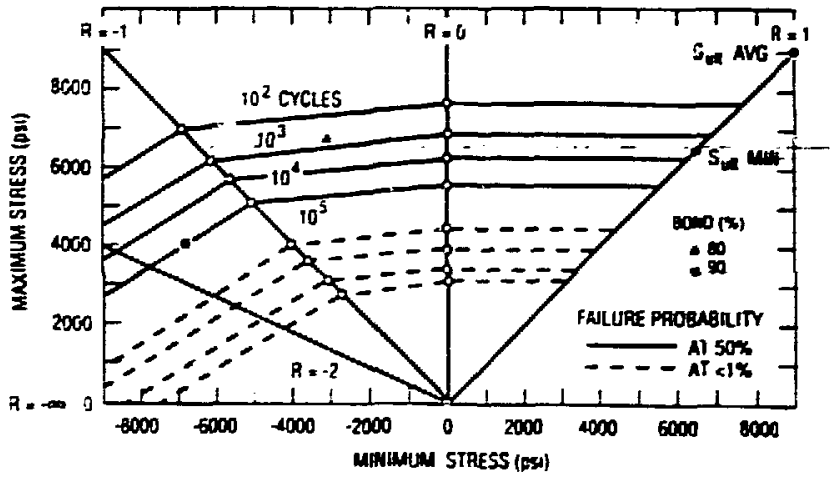

Fig. 5. Constent-life dingram for AXF-5Q graphite. probability is also shown in Fig. 5. As expected, at $<1 \%$ failure probability, neither the $80 \%$ nor the $90 \%$ bond stresses would survive for 1000 cycles.

\section{2-D ANALYSIS OF GRAPHITE AND TZM CORNER BUMPER}

A 2-D finite-element model of an AXF-5Q graphite and TZM molybdenum bumper (Fig. 6) for the ORNL/TFTR rf antenna Faraday shield was developed to determine compatibility with high- $\boldsymbol{T}_{\mathbf{i}}$ mode operation of TFTR. Three kypes of bumpers are used for horizontal, vertical, and corner locations. The corner bumper geometry was chosen for this anaiysis since it has the worst cooling path. The model consistz of 587 nodes and 525 plate elements, representing a 2$D$ plane through the corner bumper that includes the brazed interface with the TZM. The geometry model was used with MSC/NASTRAN and TOPAZ2D analysis codes to perform hea $\bar{c}$ transfer and stress analyses. Both codes, using different approsches, gave approximately the name results. TOPAZ2D was chosen is the primary heat trensfer code for its ease of operation.

A parametric load study was performed to rate the bumper for toroidal heat flux load capacity. Four loading profiles based on a maximum toroidal heat flux of $1000,2500,5000$, and $7500 \mathrm{~W} / \mathrm{cm}^{2}$ were applied, scaled to the flux rate in Fig. 4. The ralues were taken as maximum heat flux per time and normalized to the graphite surface of the bumper on the banis of plasma decay with - $1-\mathrm{cm}$ e.fold length $\left(Q=Q_{\max } e^{-R / 1 \mathrm{~cm}}\right)$.

The effect of radiation and varying thermal properties allowed an evaluation of the thermal state of the bumper after 5-min intervals (time between shots). After $300 \mathrm{~s}$, for $Q_{\max }=2500 \mathrm{~W} / \mathrm{cm}^{2}$ (suppected actual condition), the peak temperature renched $100^{\circ} \mathrm{C}$ from a start of $20^{\circ} \mathrm{C}$, eatablishing in $80^{\circ} \mathrm{C}$ ratchet in peak temperatures between shots. The resulting stress and ysis bore a maximum principal stress of 2670 psi. The same anclyais was performed for each loed case.

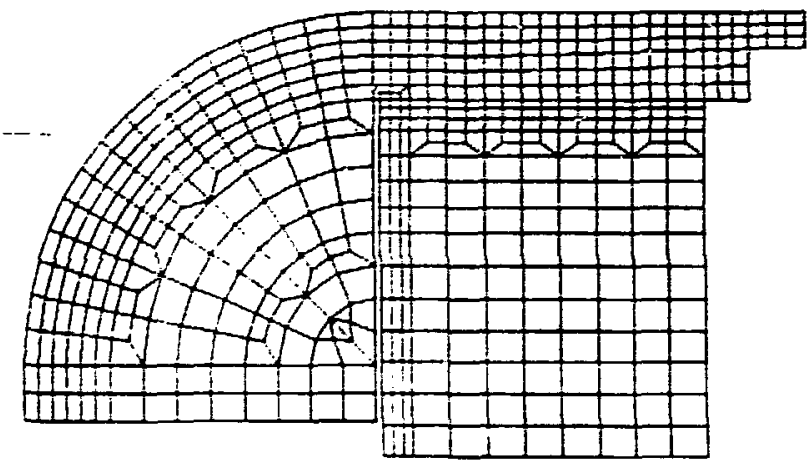

Fig. 6. AXF-5Q and TZM corner bumper model. 


\section{QUARTER-SYMMETRY SHIELD ANALYSIS}

An analysis was performed to determine the structural restraint imposed by the Faraday shield box on the Inconel 625 tubes. The shield's quarter symmetry was used to advantage to develop a refined model consisting of 9 triangular and 453 quadrilateral plate elemente, with 145 beam and 46 hexahedron (solid) elements (see Fig. 7). The model was constructed by using PDA/PATRAN and then translated to MSC/NASTRAN input format for execution.

Temperature data supplied by the 2-D thermal analyses were applied along the beam elements (frontand back-row shield tubes), with the "box" (rest of shield) at approximately room temperature. The temperatures of the front-row tubes (tubes with graphite) having the highest gradients due to proximity to the plasma caused stresses in the back-row tubes to exceed allowables.

To redistribute the load evenly between the frontand back-row tubes, runs reducing the back-row tube dimensions were performed. Feductions of 25,50, and $100 \%$, based on the back-row tubes' crost-sectional area, were performed. The original back-row tube design was a 0.50 -in. $O D$ with a 0.060 -in.-thick wall. The modified tube design would assume a 0.50 -in. $O D$ and a 0.120-in.-thick wall, turned down to achieve these reductions in area. This would also significantly reduce the moment of inertia. The $25 \%$ tube reduction provided erough selief in the weld to zeduce the maximum combined stress in a tube to $13 \mathrm{ksi}$.

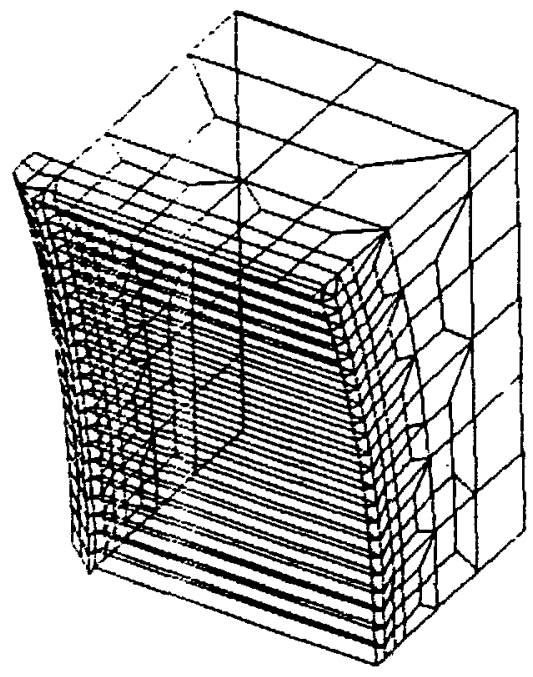

Fig. 7. Quarter-symmetry shield model.

\section{FULL-SHIELD ANA LYSIS}

The quarter-symmetry model was expanded to a lullshield model to evaluate stresses from a plasma disruption. Eddy current loads induced by the plasma disruption act as a couple with equal and opposite vertical forces on the sides of the box. Also, a running load on the tubes directed toward the plasma results from this loading. This running load is easily handled by theoretical hand calculations.

The full-shield model (Fig. 8) consists of 488 beam, 1594 plate, and 184 solid elements. Loading was applied to the vertical sides at the n! $75 \pi$ n edge as a couple The box is constrained along the rear edges (built in at frame). The disruption couple of $14,000 \mathrm{lb}$ resulted in a maximum stress of about 3700 psi on the box.

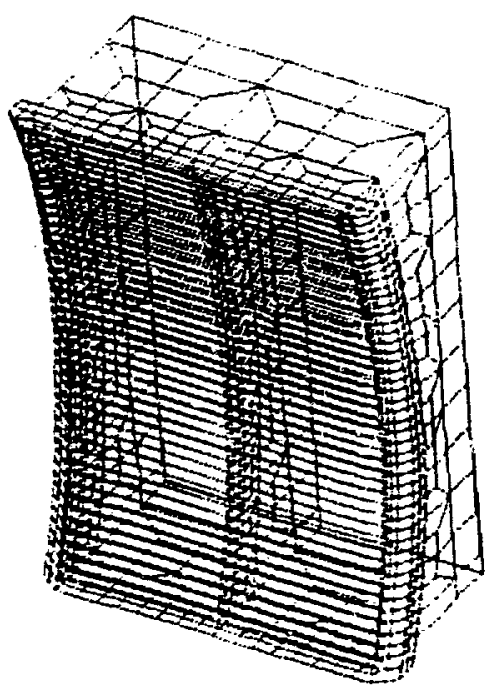

Fig. 8. Full-shield model.

\section{ANALYSIS SUMMARY}

\section{Inconel Stresses}

The stress results for the Inconel indicate that the stresses are within the ASME B\&PV Code limits in the front tubes, rear tubes, box, manifold, and manifold welds for all load cases. The tube weld stresses are well within limits for the low- $T_{i}$ loads but exceed the limit for the high- $T_{i}$ loads. The weld stresses in the back tube were lowered $40 \%$ by reducing the tube cross section and bending stiffness. Tables III-V summarize the Inconel stress results. 
Table III. Maximum fillet weld stress intensities (ksi)

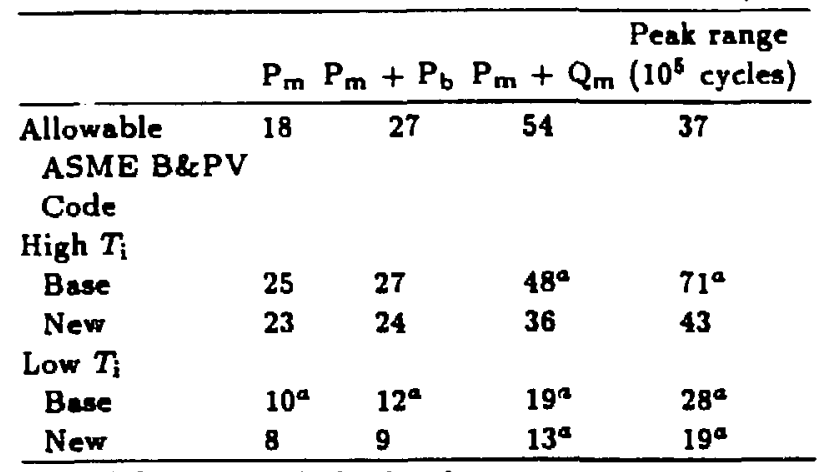

a Highest stress in back tube.

Toble IV. Maximum tube stress intensities (ksi)

Peak range
Table V. Manifold weld stresses (ksi)

\begin{tabular}{llcc}
\hline & $P_{m}$ & $P_{m}+P_{b}$ & $\begin{array}{c}\text { Peak range } \\
\left(10^{5} \text { cycles }\right)\end{array}$ \\
\hline Allowable & 18 & 27 & 73 \\
High $T_{i}$ & 3 & 6 & 30 \\
Low $T_{i}$ & 3 & 6 & 17 \\
\hline
\end{tabular}

\section{Graphite Stresses}

The stress results for the graphite indicate that the graphite tiles may develop cracks due to braxing, but there is no indication that the graphite will separate from the tube. The bumper stresses are within fatigue limits specified for graphite at loads over twice the high$T$ heating.

\section{ACKNOWLEDGMENTS}

The authors acknowledge the contributions of D. E. Williamson and J. A. Mayhall to the analysis effort. Their dedication to completion and accuracy in the thermal and fatigue analyses, respectively, helped to meet the schedule.

\section{REFERENCES}

[1] ASME Boiler and Preasure Veasel Code, Sect. VII, Div. 1 and 2. New York: The American Society of Mechanical Engineers, 1986.

\section{DISCLAIMER}

This report was prepared as an account of work sponsored by an agency of the United States Government. Neither the United States Government nor any agency thereof, nor any of their employees, makes any warranty, express or implied, or assumes any legal liability or responsibility for the accuracy, completeness, or usefulness of any information, apparatus, product, or process disclosed, or represents that its use would not infringe privately owned rights. Reference herein to any specific commercial product, process, or service by trade name, trademark. manufacturer, or otherwise does nut necessarily constitute or imply its endorsement, recommendation, or favoring by the United States Government or any agency thereof. The views and opinions of authors expressed herein do not necessarily state or reflect those of the United States Government or any agency thereof. 